\title{
THE LEGAL FRAMEWORK FOR ENSURING THE STANDARDS OF THE LIVING STANDARDS OF THE POPULATION IN UKRAINE
}

\author{
Elena LEVANDA ${ }^{1}$ \\ Research Centre of Industrial Problems of development of National Academy of Sciences of Ukraine, Ukraine
}

\begin{abstract}
The purpose of the paper is legal base in the context of the system of ensuring standards of living standards of the population of Ukraine. Methodology. The analysis of normative - legal documents on the basic level of life of different population groups. The legislative field is investigated through the official web portal of the Verkhovna Rada of Ukraine, the State statistics service of Ukraine clarified the period from 1991 to the present. Results. Functioning laws of the last century - outdated, not consistent with the goals of social policy and the contemporary economy. It is important to modernize the laws, concerning basic living standards of the population to the country's foreign policy, according to the EU methodology. Apply state social standard as a tool for poverty reduction, and the perspective tool starter package with a guaranteed standard of living government to its citizens. The practical implications. Different stages of development of economy of independent Ukraine, laid the foundations of the legislative framework of normative documents concerning social protection of the population. A country's legal framework contains a set of laws belonging to the last century, policy and regulatory documents that comply with EU standards. In turn, the regulatory framework has tenedency to the modernization of laws that establish the guaranteed state social standards and guarantees for every citizen. Value/originality. Analysis of the legislative base, revealed the ineffectiveness of the law guaranteeing basic social standard to citizens. Understanding of the process of modernization of a relatively large part of the laws adopted in the last century.
\end{abstract}

Key words: basic social standard, consumer recruitment, consumer basket and minimum consumer budget.

JLF Classification: 13, I38, K1

\section{1. Введение}

КажАый гражданин современного государства Аолжен иметь равные возможности строить жизнь по своему собственному выбору и быть застрахованным от крайних форм Аепривации (Аишения возможностей УАовметворить жизненно важные потребности). Социальная справедливость - это фактор, обеспечивающий безопасность в «завтрашнем Ане». Государственные институты Аолжны способствовать выравниванию правиц игры, когда все члены общества располагают примерно одинаковыми шансами стать социально активными, политически вмиятельными и экономически продуктивными, вносить свой вкАаА в устойчивый экономический рост и устойчивое развитие (Всемирный банк, 2005). Государство выступает гарантом Амя населения, обеспечивая каждому гражданину государственные социальные стандарты и гарантии - Закон «О государственных социальных стандартах и госуАарственных социальных гарантиях» № 2017-III от 05.10.2000г. Согмасно Аанного закона базовый социальный стандарт, есть прожиточный минимум (раздел 1, статья 6). Таким образом, доходы каждого гражданина Украины независимо от его социальной роли в обществе зависят от установленных Правительством экономических показателей прожиточного минимума на оАно мицо и Аля основных социальных и демографических групп населения. Цель работы - исследование нормативно-правовой базы в контексте системы обеспечения нормативов уровня жизни населения Украины. Проблема законодательного помя Украины относительно правовых гарантий социальной защиты населения состоит в нечеткости трактовки понятий; награможАенности нормативно-правовой базы, относительно базового социального стандарта уровня жизни; финансовых показателей установленных законом, которые не соответствует стоимости основных потребностей Аля разных групп населения в повсеАневности; не соответствии приоритетам современной социальной политики, проводимой в государстве и реальным возможностям экономики.

\section{2. Стандарты уровня жизни насекения Украины}

Миссия государства - развитие человека и человеческого потенциала, с помощью государственных

Corresponding author:

${ }^{1}$ Kharkiv Department for Macroeconomic Policy and Regional Development, Sector for Macroeconomic Analysis and Forecasting,

Research Centre of Industrial Problems of development of National Academy of Sciences of Ukraine.

E-mail: levanda2008@rambler.ru 
институтов и законодательной базы, утвержденной в стране.

Стартовой площадкой социальной защиты и социальных гарантий в Украине при переходе к рыночной экономике в 1991 г. является закон «О минимацьном потребительском бюджете» Верховный Совет УССР; Закон от 03.07.1991 № 1284-XII. Закон быи утвержден 1-м президентом независимого госуАарства Украины - $\Lambda$. Кравчуком. Цель закона «Обеспечить проведение социальной политики, направленной на подАержку наименее социально защищенных слоев населения, формирование взаимосвязанной системы минимальных Аоходов и расходов государства на их содержание в учреждениях социальной сферы». Минимамьный потребительский бюАжет (МПБ) - это набор продовольственных и непродовольственных товаров и услуг в натуральном и стоимостном выражении, обеспечивающий удовлетворение основных физиологических и социально-культурных потребностей человека. МПБ формируется нормативным методом на основе системы потребительской корзины, научно обоснован. Стоимостная оценка МПБ пересматривается с учетом индекса цен на потребительские товары и ускуги.

МПБ служит ориентиром стоимости жизни Аля населения с низкими доходами и мотивацией Аля правительства, как социального стандарта уровня жизни, который заслуживают гражАане Украины в условиях увеличения показателей экономики в стране. МПБ был сформирован в период становления Украины как независимого государства. Нормативно-правовая база выходит из переходных законов бывшего СССР. Анализ митературы по Аанному вопросу - ограничен. МПБ гарантирует гражАанам равные шансы быть здоровыми, экономически проАуктивными, социально активными. Статус в законоАательном поле - Аействующий, оАнако на практике находиться в «цатентной форме».

С 1994 по 1999 гг., экономика Украины находится в кризисных условиях. Разрабатывается и утвержАается Закон Украины N 190/94-ВР «О черте мало обеспеченности» от 04.10.1994 г. Согласно ст. 46 Конституции Украины (254к / 96-ВР) «Пенсии, Аругие виды социальных выплат и пособий, являющиеся основным источником существования, Аолжны обеспечивать уровень жизни не ниже прожиточного минимума, установленного законом». Таким образом, население Аолжно быть социально защищенным. В этот период устанавливается социальный норматив - черта мало обеспеченности. Величина среАнеАушевого совокупного Аохода, который обеспечивает нетрудоспособным гражАанам потребление товаров и услуг на минимальном уровне, установленном законодательством. Применяется предел мало обеспеченности Аля определения размеров социальных гарантий и социальной помощи. Закон закладывает правовую основу осуществления аАресной материальной ПоААержки наименее социацьно защищенных слоев насемения в условиях кризисного состояния экономики (http://zakon3.rada.gov.ua/ laws/show/190/94-\%D0\%B2\%D1\%80). В Аальнейшем он становится основой закона «О прожиточном минимуме».

В настоящее время этот закон применяется к нетруАоспособным гражАанам, которые получают пенсию, и среАнеАушевой совокупный АОхоА семей не превышает векичины стоимости черты мало обеспеченности (http://zakon5.rada.gov.ua/laws/show/1282-12). Применяется нормативно-статистический метоА. Продовольственные товары определяются в соответствии с социальными нормами потребления Аля нетрудоспособного возраста - нормативным метоАом. Стоимость непродовольственных товаров и услуг и стоимость на содержание жилья, определяются в соответствии с фактическими расходами семей с низкими Аоходами. Стоимость непродовольственных товаров не может составцять менее $15 \%$ от стоимости продуктового набора (http://zakon3.rada.gov.ua/ laws/show/190/94-\%D0\%B2\%D1\%80). Величина стоимости черты мало обеспеченности один раз в гоА утвержАается и прописывается в Государственном бюджете Украины, Верховным Советом Украины. Может пересматриваться в соответствии с ростом индекса цен на потребительские товары и услуги вместе с уточнением показателей Государственного бюАжета Украины. В исключительных случаях Верховный Совет Украины может утвердить величину стоимости черты мало обеспеченности без утверждения государственного бюджета Украины. Статус закона - действующий в законодательной базе.

В 1999 году в условиях реконструкции экономики Украины был принят Закон Украины № 966-XIV «О прожиточном минимуме» от 15.07.1999. Он заложил правовые основы реализации государством конституционной гарантии гражАан на достаточный жизненный уровень (ст. 46 Конституции Украины (254к/96-ВР)). Прожиточный минимум - это стоимостная величина Аостаточного Амя обеспечения нормального функционирования организма человека, сохранения его здоровья набора продуктов питания, а также минимального набора непродовольственных товаров и минимального набора услуг, необходимый Аля удовлетворения основных социальных и культурных потребностей мичности. В разрезе украинская потребительская корзина определяет величину прожиточного минимума каждого украинца - согласно постановлению №780 «Об утверждении наборов продуктов питания, наборов непродовольственных товаров и услуг Аля основных социальных и демографических групп насемения», от 11.10.2016 г. (преАыАущая версия методика №656, п.1 от 14.04.2000 г). Аля расчета прожиточного минимума используются среАние потребительские цены (тарифы) в 
стране (регионе), пункт 1.5 (http://ukrstat.org/uk/ metod_polog/metod_doc/2006/519/519.htm). Стоимость пожиточного минимума оценивается в текущих ценах, корректируются исходя из развития и возможностей экономики. Согласно Конституции Украины, прожиточный минимум является базовым социальным стандартом и государственным регумятором бюджета Украины, при утверждении показателей на гоА.

Указом Президента Украины N 637/2001 (637/2001) от 15.08.2001 р., впервые официально в стране утвердили черту бедности («Стратегия преодоления беАности»). Черта беАности - это уровень Аохода, ниже которого невозможно удовметворение основных потребностей. Черта беАности рассчитывается по фиксированной долей среАнеАушевого Аохода (расходов) - 75\% медианного уровня совокупных доходов (расходов) в расчете на условного взрослого на основании Аанных выборочного обслеАования условий жизни Аомохозяйств, проводится Государственной службой статистики Украины. Аля определения черты беАности используют показатель расходов (это связано с тем, что в стране развита теневая экономика, и доходы деятельности гражАан не зарегистрированы в государственных институтах). Из этого следует, что черта бедности опредемяет масштабы и уровень бедности в стране. В законодательном поле Аает общую оценку уровня жизни населения.

В 2012 году, согласно Приказа № 629/1105/1059/408/612 «Методика комплексной оценки беАности» от 08.10.2012 и Приказа № 114/242/392/85/85 «Методика проведения мониторинга и оценки эффективности программ социаАьной подАержки населения $\gg$ от 12.03.2013 - рассчитывают существующие в современности черты бедности. «Методика проведения мониторинга и оценки эффективности программ социальной поААержки насемения» предусматривает расчет системы показателей, которые формируются на основе обслеАования Аомохозяйств, статистических и аАминистративных данных, относительно бедности. Устанавливает предел бедности по относительному критерию (опреАеляется по фиксированной Аолей среднедушевых совокупных расходов) - 75\% меАианного уровня среднеАушевых эквивалентных совокупных расходов в расчете на одну условную мичность и черту бедности по абсолютному критерию - размер законодательно установленного прожиточного минимума в расчете на месяц на одного человека. По относительному критерию с использованием показателя «эквивалентные совокупные расходы в расчете на оАно мицо» осуществяяет Институт демографии и социальных исследований им. Птухи (Аалее - НАН Украины). По абсолютному критерию с использованием показателя «эквивалентные общие доходы в расчете на оАно мицо» осуществмяет Государ- ственная служба статистики Украины, пункт 1.4 (http://zakon2.rada.gov.ua/laws/show/z0508-13). Рассчитывается один раз в гоА. Цель - отследить изменения в численности получателей помощи, объемы и суммы выплат, оценить влияние на бедность, Аейственность и аАресность помощи, пункт 1.7 (http://zakon2.rada.gov.ua/laws/show/z0508-13). «Методика комплексной оценки бедности» утвержАает уже существующие границы беАности в Приказе № 114/242/392/85/85 от 12.03.2013 и Аругие: границу крайней бедности, определенная по относительному критерию 60\% медианного уровня среАнеАушевых эквивалентных совокупных расходов. ААаптирована к критерию Европейского Союза; границу абсолютной беАности, опреАеляется по критерию стоимости суточного потребления на уровне 5 Аомларов США в соответствии с паритетом покупательной способности (гривневый эквивалент 5 Аомларов США по паритету покупательной способности рассчитывается Всемирным банком), используют Аля сравнения с межАународными показателями. Расчеты осуществляются ежеквартально на основании данных выборочного обследования условий жизни Аомохозяйств Государственной службой статистики Украины, пункт 1.3, 1.6 (http://zakon3.rada.gov.ua/laws/show/z1785-12). Цель - выполнение Государственной целевой социальной программы преодоления и предотвращения беАности.

С 2002 года вводится расчет индекса потребительских цен (ИПЦ) по межАународной классификации инАИвиАУацьного потребления по целям (COICOPHBS (1997)) - товары и услуги, наиболее репрезентативные и важные Аля всех домашних хозяйств. Рассчитывается ИПЦ на основе «Потребительского набора» Государственной службы статистики. Потребительский набор - еАиный Аля всех регионов страны репрезентативно отобранный перечень товаров и услуг, чаще всего потребляющий населением. ИПЦ характеризует изменения во времени общего уровня цен на товары и ускуги, которые покупает население Аля непроизводственного потребления. Методология расчета ИПЦ базируется на общих требованиях Конвенции 160 МежАународной организации труда 1985 года (статья 12), «Резолюции по индексам потребительских цен», принятой на 17 МежАународной конференции статистиков труда (2003) и совместном Аокументе МОТ, МВФ, ОЭСР, Евростата, ООН и Всемирного банка «РуковоАство по индексу потребительских цен. Теория и практика» (2004). Наблюдение за изменениями потребительских цен (тарифов) на товары (услуги) осуществляется на центральном уровне и является репрезентативным Амя расчета ИПЦ Аһя кажАого региона страны (гипермаркеты и супермаркеты, торговые центры, среАние, маленькие и Ар. специамизированные магазины), кроме сельской местно- 
сти. Отражает реальную структуру потребительских Аенежных расходов Аомохозяйств; оптимальную организацию процесса регистрации цен; современные потребности украинцев и их структуру потребления продовольственных и непродовольственных товаров и услуг. Показатель ИПЦ характеризует уровень инфмяции, который используется в государ- ственной политики Аля анализа и прогноза ценовых процессов в экономике, пересмотра Аенежных АохоАов населения, перерасчета показателей системы национальных счетов в постоянные цены, обеспечивает проведение межАународных сопоставлений.

Потребительский набор, это удовлетворение актуальных потребностей насемения в сложившихся

Государственные социальные стандарты и гарантии для населения Украины

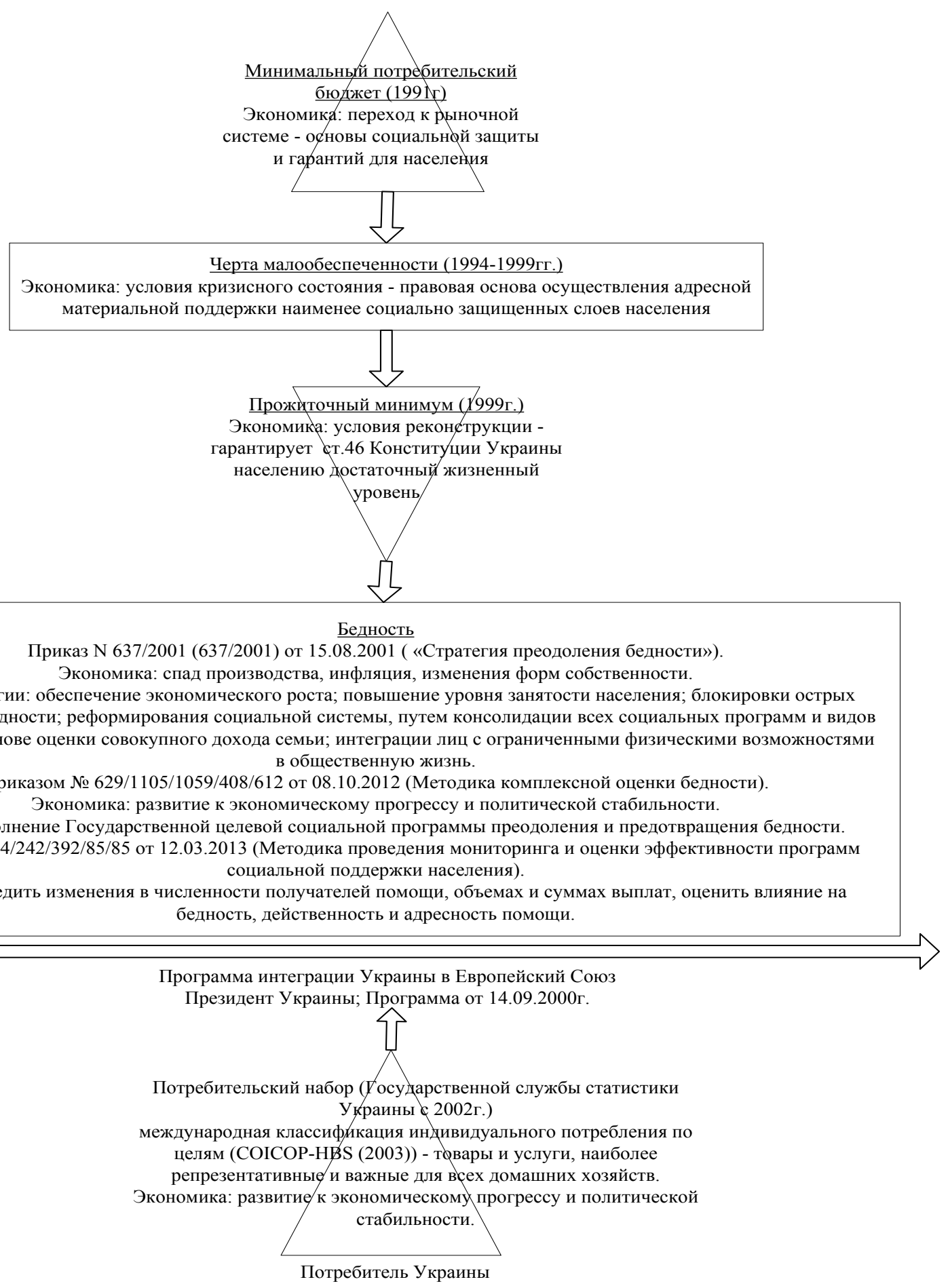

Рис. 1. Государственные социальные стандарты и гарантии независимой Украины 
условиях экономики. ИПЦ фиксирует экономическую состав яющую, кажАого Аомохозяйства «зАесь и сейчас». С помощью установменного ИПЦ индексируются государственные социальные гарантии Аля насемения. Структура потребительского набора, соответствует стандартам Евросоюза, аАаптирована к современным условиям Украины, включая все сферы жизни населения.

Государственные социальные стандарты и гарантии Аля населения Украины с 1991 г. по настоящее время (рис. 1).

\section{3. Спецификация потребитемьских бюАжетов в Украине}

В правовом поле Украины на сегодняшний день Аействуют три потребительских бюАжета: Минимальный потребительский бюджет (МПБ); Базовый социальный стандарт - прожиточный минимум (ПМ); Потребитемьский набор (ПН) Государственной службы статистики Украины. Аействующие потребительские бюАжеты относятся к разным моделям уровня жизни. Отличия состоят в норме потребления, структуре спецификации, ассортимента товаров и ускуг, стоимости потребитемьских корзин.

Из таблицы 1 виАно, что «Потребительский набор» Государственной службы статистики состоит из 12 групп спецификаций. УАовлетворяет фактические потребности всех групп насемения Украины «здесь и сейчас». Методология - Государственная служба статистики Украины, Приказ №
190 от 01.07.2013г. (с изменениями, Приказ № 371 от 28.11.2014г. и Приказ № 315 от 05.11.2015 г. методологические положения по организации статистического наблюдения за изменениями цен (тарифов) на потребительские товары (ускуги) и расчетов индексов потребительских цен. «Потребительский набор» утвержАается Государственной службой статистики Украины вместе с межвеАомственной группой - специалисты Министерства экономического развития Украины, Национацьного Банка Украины, профсоюзов, ученые. Соответствует методологии Евросоюза. «Минимальный потребительский бюАжет» - состоит из 10 групп спецификаций. УАовлетворяет основные физиологические и социально - кумьтурные потребности мичности. Методология - Постановление N 244 «О минимацьном потребительском бюАжете» от 3.10.1991 г. В расчете состава корзины участвуют профсоюзы и общество защиты прав потребителей. Аахее бюАжет проходит научно-общественную экспертизу при Кабинете Министров Украины (КМУ) и утвержаается Аанным ведомством. Население: оАно Аицо или семьи разного типа. Прожиточный минимум - состоит из 9 групп спецификаций. УАовметворяет физиологические, основные социальные и культурные потребности мичности. Методология - Приказ №109 / 95/157 «Методика опреде-

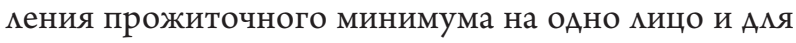
Аиц, относящихся к основным социальных и Аемографических групп населения» от 17.05.2000 г. Расчет состава корзины производит Министерство социальной политики Украины, Министерство

Таблица 1

Спецификация потребительских бюАжетов в Украине

\begin{tabular}{|c|c|c|c|c|}
\hline № $\Pi / \Pi$ & Спецификация & $\begin{array}{c}\text { Потребительский набор } \\
\text { Приказ Госуаарственной } \\
\text { скужбы статистики Украины } \\
\text { № } 158 \text { от } 29.08 .2016 \text { г. }\end{array}$ & $\begin{array}{c}\text { Прожиточный минимум } \\
\text { Закон Украины № 966- } \\
\text { XIV, ст. 4. от 15.07.1999 г. } \\
\text { Постановмение №780 от } \\
11.10 .2016 \text { г. }\end{array}$ & $\begin{array}{c}\text { Минимальный } \\
\text { потребительский бюАжет } \\
\text { Закон Украины } \\
\text { № 1284-XII от 03.07.1991г. }\end{array}$ \\
\hline 1. & $\begin{array}{l}\text { Питания и безалкогольные } \\
\text { напитки }\end{array}$ & ++ & $+/+$ & $+/-$ \\
\hline 2. & $\begin{array}{l}\text { Алкогольные напитки и } \\
\text { табачные изделия }\end{array}$ & ++ & $-/-$ & + \\
\hline 3. & ОАежАа и обувь & ++ & + & + \\
\hline 4. & $\begin{array}{l}\text { Жилье, вода, электроэнергия, } \\
\text { газ и Аругие виды топлива }\end{array}$ & ++ & + & + \\
\hline 5. & $\begin{array}{l}\text { Бытовая техника и текущее } \\
\text { обскуживание }\end{array}$ & ++ & + & + \\
\hline 6. & 3Аоровье & ++ & $-/+$ & + \\
\hline 7. & Транспорт & ++ & + & + \\
\hline 8. & Коммуникации & ++ & + & + \\
\hline 9. & Отаых, культура & ++ & $-/+$ & $-/+$ \\
\hline 10. & Образование & ++ & $-/+$ & + \\
\hline 11. & Рестораны и гостиницы & ++ & - & - \\
\hline 12. & Смешанные товары и ускуги & ++ & - & + \\
\hline \multicolumn{2}{|r|}{ Итого: } & 12 & 9 & 10 \\
\hline
\end{tabular}

Источник: сайт Верховного Совета Украины 
финансов Украины, Министерство Охраны 3Аоровья Украины, Министерство экономического развития Украины, преАставители Профсоюзов и работоАателей. Утверждается КМУ.

Все бюАжеты утвержАаются оАин раз в гоА и пересматриваются, раз в пять мет. ОАнако базовый социальный стандарт был пересмотрен и утвержден через 16 мет с момента его функционирования на социацьно-экономической платформе Украины. Аанное Аействие противоречит законодательной базе страны.

\section{4. Исследование законодательного поля нормативов уровня жизни населения}

Исследование нормативно-правовой базы в контексте системы обеспечения нормативов уровня жизни, Аал оценку функционирования населения в рамках законодательной системы в повседневности. Законодательное поле исследовано с помощью официального веб-портала Верховной Рады Украины, официального сайта Государственной службы статистики Украины. Анализ показац, что большая часть законов, соприкасающихся с внутренней политикой Украины характерны Аля политики прошлого столетия. В настоящее время в условиях инновационного развития страны, законодательная база нужАается в модернизации и изменении фундаментальных законов, относительно законов социальной защиты насемения. Социальная политика не должна строить фунАамент социальной защиты на принципах «прошлого опыта». Базовый социальный станАарт, используется правительством как инструмент борьбы с бедностью, что не соответствует политики государства в условиях интеграции в ЕС. Население не обучено, как вести зАоровый, экономный и социально активный образ жизни. Внешней помитики Украины, соответствует «Потребительский набор» Государственной службы статистики Украины. ААаптирован и протестирован с 2002 года к нынешнему законодательству, жизнедеятельности населения и отвечает методологии ЕС. Сегодня «Потребительский набор» применяется в рамках межАународной статистики и как адаптер социацьных гарантий во времени. Из этого следует, что законодательная база внутренней политики Украины устарема и илет парамлемьно с нормативными Аокументами, отвечающих внешней политики страны.

\section{5. Выводы}

Переход Украины к рыночной экономики в 1991 году заложил основу социальной защиты и социальных гарантий Аля населения, закон «О минимальном потребительском бюАжете». Модель - социального стандарта уровня жизни. В условиях реконструкции экономики Украины в 1999 году, быц основан закон «О прожиточном минимуме». Модель - Аостаточный жизненный уровень. В условиях интеграции Украины в Европу, 2002 гоА - Классификация индивидуальных потребностей по целям (Аалее потребительский набор Государственной службы статистики Украины). Модель - приемлемый уровень жизни. Выполняя роль государственного базового социального стандарта в законодательстве - прожиточный минимум применяется и используется в реальной экономике в качестве номинального показателя Амя расчета социальных гарантий (социальной помощи, минимальный Аолжностной оклаА и минимальная заработная пиата, пенсии, стипендии). Не отображает актуальные потребности населения. Государство не может обучить насемение, как строить зАоровую, экономную, социально активную жизнь в обществе, из-за несоответствия стоимости базового социацьного стандарта, заложенного в бюАжете и фактической стоимости основных потребностей в повсеАневности. Нормативно-правовая база по отношению к базовому социальному стандарту имеет большую нагрузку и сталкивается с большим количеством нормативных Аокументов, нет четкости в экономических показатемях, Аоступности в понятиях нормативных Аокументов, последовательности применения законов.

Переориентация социальной политики от политики прошиого столетия к современности, позволит модернизовать каркас законов, относительно стандарта уровня жизни населения в реальных возможностях развития экономики. Применять государственный социальный стандарт не как инструмент борьбы с беАностью, а в ракурсе инструмента стартового пакета гарантированного уровня жизни государством своим гражАанам. Базовый социальный стандарт Аолжен мотивировать население к социальной «полезности», в связи с этим Аолжен иАти с функцией справеАливости. Аифференцировать социальную справеАливость по стандартам уровня жизни Аля разАичных слоев насемения (Аецильные группы), согласно КИПЦ

\section{References:}

Obzornyj doklad o mirovom razvitii 2006. Socialnaya spravedlivost' i razvitie. Vsemirnyj bank. Vashington: federalnyj okrug Kolumbiya. 2005. 34 s.

Zakon Ukrayiny «Pro prozhytkovyy minimum»: Zakon vid 15.07.1999 №966-XIV [Elektronnyi resurs]. Retrieved from: http://zakon2.rada.gov.ua/laws/show/966-14

Zakon Ukrayiny «Pro mezhu malozabezpechenosti»: Zakon vid 04.10.1994 №190/94-VR [Elektronnyi resurs]. Retrieved from: http://zakon3.rada.gov.ua/laws/show/190/94-\%D0\%B2\%D1\%80

Zakon Ukrayiny «Pro indeksatsiyu hroshovykh dokhodiv naselennya $\gg$ : Zakon VR URSR vid 03.07.1991 №1282XII [Elektronnyi resurs]. - Retrieved from: http://zakon5.rada.gov.ua/laws/show/1282-12 
Nakaz № 519 «Pro zatverdzhennya Metodolohichnykh polozhen' shchodo orhanizatsiyi statystychnoho sposterezhennya za zminamy tsin (taryfiv) na spozhyvchi tovary (posluhy) i rozrakhunku indeksu spozhyvchykh tsin» vid 14.11.2006. Derzhstat Ukrayny [Elektronnyi resurs]. - Retrieved from: http://ukrstat.org/uk/metod_ polog/metod_doc/2006/519/519.htm

Nakaz №114/242/392/85/85 «Metodyka provedennya monitorynhu ta otsinyuvannya efektyvnosti prohram sotsial'noyi pidtrymky naselennya $\gg$ vid 12.03.2013 [Elektronnyi resurs]. - Retrieved from: http: //zakon2.rada. gov.ua/laws/show/z0508-13

Nakaz №629/1105/1059/408/612 «Metodyka kompleksnoyi otsinky bidnosti» vid 08.10.2012 [Elektronnyi resurs]. - Retrieved from: http://zakon3.rada.gov.ua/laws/show/z1785-12

Nakaz №480 «Pro zatverdzhennya Klasyfikatsiyi indyvidual'noho spozhyvannya za tsilyamy» vid 29.12.2007. Derzhstat Ukrayny [Elektronnyi resurs]. - Retrieved from: http://www.ukrstat.gov.ua/norm_ doc/2007/480_2007.htm

Nakaz №158 «Pro zatverdzhennya metodolohichnykh polozhen' shchodo orhanizatsiyi statystychnoho sposterezhennya za zminamy tsin (taryfiv) na spozhyvchi tovary (posluhy) i rozrakhunkiv indeksiv spozhyvchykh tsin» vid 29.08.2016. Derzhstat Ukrayny [Elektronnyi resurs]. - Retrieved from: http://www.ukrstat.gov.ua/ metod_polog/metod_doc/2016/158/158_2016.htm

Zakon Ukrayiny «Pro derzhavni sotsial'ni standarty ta derzhavni sotsial'ni harantiyi»: Zakon vid 05.10.2000 №2017-III [Elektronnyi resurs]. - Retrieved from: http://zakon2.rada.gov.ua/laws/show/2017-14

Zakon Ukrayiny «Pro minimal'nyy spozhyvchyy byudzhet»: Zakon VR URSR vid 03.07.1991 №1284-XI [Elektronnyi resurs]. - Retrieved from: http://zakon2.rada.gov.ua/laws/show/1284-12

Zakon Ukrayiny «Pro derzhavnu sotsial'nu dopomohu malozabezpechenym sim»yam»: Zakon vid 01.06.2000 № 1768-III-VRU [Elektronnyi resurs]. - Retrieved from: http://zakon2.rada.gov.ua/laws/show/1768-14

Zakon Ukrayiny «Pro Derzhavnyy byudzhet Ukrayiny na 2016 rik»: Zakon vid 25.12.2015 №928-VIII [Elektronnyi resurs]. - Retrieved from: http://zakon0.rada.gov.ua/laws/show/928-19

Postanova Ukrayiny «Pro naukovo-hromads'ku ekspertyzu naboru produktiv kharchuvannya, naboru neprodovol'chykh tovariv i naboru [...] «: Postanova № 1767 KMU vid 24.09.1999 [Elektronnyi resurs]. Retrieved from: http://zakon3.rada.gov.ua/laws/show/1767-99-\%D0\%BF

Postanova Ukrayiny «Pro zatverdzhennya Polozhennya pro vyznachennya vartosti neprodovol'chykh tovariv i posluh ta vartosti utrymannya zhytla pry formuvanni mezhi malozabezpechenosti»: Postanova № 310 vid 01.03.1999 [Elektronnyi resurs]. - Retrieved from: http://zakon0.rada.gov.ua/laws/show/310-99-\%D0\%BF

Postanova Ukrayiny «Poryadok provedennya indeksatsiyi hroshovykh dokhodiv naselennya»: Postanova N 1078 KMY vid 17.07.2003p [Elektronnyi resurs]. - Retrieved from: http://zakon0.rada.gov.ua/laws/show/1078-2003$\% \mathrm{D} 0 \% \mathrm{BF}$

Postanova Ukrayiny « Pro zatverdzhennya naboriv produktiv kharchuvannya, naboriv neprodovol'chykh tovariv ta naboriv posluh dlya [...] «: Postanova № $656 \mathrm{KMU}$ vid 14.04.2000p [Elektronnyi resurs]. - Retrieved from: http://zakon0.rada.gov.ua/laws/show/656-2000-\%D0\%BF

Nakaz № 519 «Pro zatverdzhennya metodolohichnykh polozhen' shchodo orhanizatsiyi statystychnoho sposterezhennya za zminamy tsin (taryfiv) na spozhyvchi tovary (posluhy) i rozrakhunku indeksu spozhyvchykh tsin» vid 14.11.2006. Derzhstat Ukrayny [Elektronnyi resurs]. - Retrieved from: http://ukrstat.org/uk/metod_ polog/metod_doc/2006/519/519.htm

Nakaz №190 zi zminamy vid 01.07.2013, zatverdzhenymy nakazamy № 371 vid 28.11.2014 ta № 315 vid 05.11.2015. Derzhstat Ukrayny [Elektronnyi resurs]. - Retrieved from: http://www.ukrstat.gov.ua/metod_polog/metod_ doc/2013/190/190_2013.htm

Nakaz №109/95/157 «Pro zatverdzhennya Metodyky vyznachennya prozhytkovoho minimumu na odnu osobu ta dlya osib, yaki vidnosyat'sya do osnovnykh sotsial'nykh i demohrafichnykh hrup naselennya $\gg$ vid $17.05 .2000 \mathrm{p}$ [Elektronnyi resurs]. - Retrieved from: http: http://zakon3.rada.gov.ua/laws/show/z0347-00

Nakaz Prezydenta Ukrayiny L. Kuchma № 637/2001 «Pro stratehiyu podolannya bidnosti» vid 15.08.2001. Derzhstat Ukrayny [Elektronnyi resurs]. - Retrieved from: http://www.ukrstat.gov.ua

Konstytutsiya Ukrayiny: Zakon vid 28.06.1996 № 254к/96 - VR [Elektronnyi resurs]. - Retrieved from: http: //zakon2.rada.gov.ua/laws/show/254\%D0\%BA/96-\%D0\%B2\%D1\%80

Ministerstvo sotsial'noyi polityky Ukrayiny [Elektronnyi resurs]. - Retrieved from: http://www.mlsp.gov.ua/ labour/control/uk/index 


\section{Елена ЛЕВАНДА}

\section{ЗАКОНОДАТЕЛЬНАЯ БАЗА СИСТЕМЫ ОБЕСПЕЧЕНИЯ НОРМАТИВОВ УРОВНЯ ЖИЗНИ НАСЕЛЕНИЯ В УКРАИНЕ}

Аннотация. Цель статьи - исследовать нормативно-правовую базу в контексте системы обеспечения нормативов уровня жизни населения Украины. Методология. Анализ нормативно-правовых документов, относительно базового уровня жизни разных групп населения. Законодательное поле исследовано с помощью официального веб-портала Верховной Рады Украины, официального сайта Государственной службы статистики Украины. В работе осветляется период с 1991 года по настоящее время. Результаты. Функционирующие законы прошлого столетия - устарели, не соответствуют целям социальной политики и современным возможностям экономики. Важно модернизировать свод законов, относительно базового стандарта уровня жизни населения к внешней политики страны, согласно методологии ЕС. Применять государственный социальный стандарт не как инструмент борьбы с бедностью, а в ракурсе инструмента стартового пакета гарантированного уровня жизни государством своим гражданам. Практические последствия. Разные стадии развития экономики независимойУкраины, заложили основы в законодательной базе нормативных документов, относительно социальной защиты населения. Законодательная база страны содержит свод законов, принадлежащих к политике прошлого столетия так и нормативные документы, отвечающие стандартам ЕС. В свою очередь нормативно-правовая база имеет тенденцию к модернизации законов, которые устанавливают гарантированный государственный социальный стандарт и гарантии для каждого гражданина. Ценность/оригинальность. Анализ законодательной базы, раскрыл неэффективность закона, гарантирующего базовый социальный стандарт гражданам. Понимание процесса модернизации относительно большей части законов, принятых в прошлом столетии. 